\title{
Effect of Heated Humidification on Adherence to Continuous Positive Airway Pressure Therapy in Subjects With Obstructive Sleep Apnea and Nasopharyngeal Symptoms
}

Numerous studies have demonstrated the efficacy of CPAP therapy for reducing symptoms (eg, daytime sleepiness), improving quality of life (QOL), reducing the risk of driving and occupational accidents, and preventing sequelae of obstructive sleep apnea (OSA), such as cardiovascular morbidity and mortality..$^{1-3}$

Many patients have trouble complying with CPAP therapy even though it is effective. ${ }^{4}$ As many as $46-73 \%$ of patients undergoing nasal CPAP therapy report considerable local persistent side effects, such as congestion, burning, sneezing, or dryness, $, 5,6$ which can impair adherence to the therapy. ${ }^{7}$ As a result, patients perceive that the therapy will cause problems and consequently refuse it. Therefore, interventions to treat these side effects could improve adherence and provide better QOL.

Heated humidification was developed for patients undergoing CPAP who experience chronic nasal congestion. ${ }^{4}$ The palatal seal, by which the uvula closes the nasopharynx, is not always complete during CPAP, leading to leaks. ${ }^{5}$ Mouth leaks during CPAP therapy seem to be particularly substantial, because use of CPAP can lead to elevated inspiratory air flow across the nasal and oral mucosa, because the nasal mucosa cannot compensate for the water transferred to inspired gases during expiration. Flow of cold air and mouth leaks through the nasal passage during nasal CPAP management generate a subjective sense of nose and mouth dryness, nasal congestion, and enhanced nasal resistance, ${ }^{6}$ which cause local nerves to secrete leukotrienes and vasoactive amines to increase nasal airway resistance ${ }^{7}$ leading to mouth breathing, a potent mechanism of oropharyngeal dryness. ${ }^{6}$ Oral dryness can change the oral flora and increase the risk for aspiration pneumonia. ${ }^{8}$ Heated humidification breaks the vicious circle produced by mouth leaks during nasal CPAP management in patients complaining of upper airway symptoms. ${ }^{9}$ Prior research has demonstrated that heated humidification pre-

Correspondence: Harun Karamanlı MD Sanatoryum Avaneu $06280 \mathrm{Ke}-$ cioren - Ankara, Turkey. E-mail: drharun@ hotmail.com.

The author has disclosed no conflicts of interest.

DOI: $10.4187 /$ respcare. 05122 vents dehydration from CPAP with a nasal mask leak by increasing absolute humidity. ${ }^{7}$ A clinical consensus has been reached that humidifiers should be used to treat local side effects related to nasal CPAP management to enhance humidity and heat in respired air. ${ }^{6}$ Consensus statements and guidelines for noninvasive ventilation include contradictory recommendations regarding humidification. ${ }^{10,11}$

Humidity decreases congestion and dryness in patients with OSA, and heated humidification and cold pass-over humidity are frequently utilized to alleviate these symptoms. However, little is known about the effects of these kinds of humidity on adherence to CPAP therapy or nasal symptoms in patients with OSA. Heated humidification considerably improves daily adherence by $39 \mathrm{~min}$, compared with that of cold pass-over humidification in patients with OSA. ${ }^{12}$ The greater adherence was due to the relatively high proportion of patients with nasal symptoms (eg, 58\% dry throat and 60\% nasal congestion before therapy). These crossover studies recommend that adherence to nasal CPAP can be improved if all subjects use heated humidification at the beginning of nasal CPAP treatment. However, only patients with considerable upper airway problems may benefit from heated humidification. Several CPAP studies have been performed with and without heated humidification at the beginning of treatment for 1 or 2 nights ${ }^{13,14}$; it was concluded that heated humidification offered no added benefit concerning further CPAP adherence.

Sleep center clinicians should consider pharyngeal and nasal dryness, because these symptoms can be diminished effectively by heated humidification. Although no consensus has been reached regarding the ideal level of air humidification, ${ }^{15,16}$ nasal CPAP management using heated humidification has become a standard method. However, heated humidification does not prevent all side effects. Furthermore, supplementing with a humidifier adds considerable cost and difficulty to nasal CPAP treatment and complicates the practical process (hygiene, transport). ${ }^{17}$

Age strongly predicts the necessity for heated humidification in patients with OSA. ${ }^{18}$ This is not surprising, because the nose is a highly dynamic organ that undergoes considerable functional alterations during aging. Many agedependent changes in the nose have been identified, in- 
cluding an increased probability of nasal symptoms, ${ }^{19}$ increased nasal resistance, ${ }^{19,20}$ and/or a deterioration of nasal mucociliary function..$^{21}$ Age $>60$ y predicts the need for heated humidification. ${ }^{18}$

Uvulopalatopharyngoplasty; surgical ear, nose, and throat procedures; and chronic disturbances of the nasal mucosa suggest the need for additional heated humidification. ${ }^{18}$ Patients who undergo an ear, nose, and throat operation are the most likely to benefit from supplemental humidification in terms of better adherence, improved QOL, and sleepiness, ${ }^{22}$ because they are aware of the support needed for mouth leaks during therapy and the possible reasons for lack of adherence to nasal CPAP treatment. ${ }^{18}$

All undesirable dryness during ventilation with mouth leaks is diminished by heated humidification and is entirely removed by the face mask. ${ }^{9}$ Unfortunately, despite the benefits of a full mask to diminish nasal problems, a nasal mask is more beneficial than a face mask. ${ }^{23}$

CPAP adherence rates are $40-78 \% .{ }^{24}$ Because QOL and sleep are influenced by dryness in the upper respiratory tract related to CPAP, the temperature and humidity of inspired air should be increased by heated humidification. The authors determined no benefit of starting heated humidification with CPAP therapy compared with prescribing heated humidification during follow-up.

A previous study ${ }^{25}$ showed that improved adherence to nasal CPAP may significantly improve QOL and postulated a considerable advantage of adding heated humidification to CPAP with a substantial air leak. Adherence to treatment justifies heated humidification in patients with OSA complaining of a nasal disturbance despite the extra financial cost. ${ }^{26}$

In contrast, a few previous studies did not obtain parallel outcomes. Ryan et $\mathrm{al}^{27}$ compared 4-week use of dry CPAP, CPAP with heated humidification, and CPAP with a supplementary topical nasal steroid in 125 subjects with a diagnosis of OSA (apnea-hypopnea index $\geq 10$ events/h) and showed that CPAP with heated humidification decreases the frequency of nasal complaints; however, adherence rates and QOL remained unchanged by these interventions.

In this issue of the Journal Soudorn et $\mathrm{al}^{28}$ compared subjects with OSA with nasopharyngeal symptoms living in a tropical climate. This investigation's subjects were randomly assigned to accept CPAP with or without heated humidification. CPAP adherence and QOL appeared to be improved when heated humidification was used in subjects with OSA with nasopharyngeal symptoms even in a tropical climate. This investigation's conclusions differ from those of other studies regarding the timing of use of heated humidification and patient selection. This study selected the group of subjects who experienced symptoms with nasal-oral side effects during the first night of the CPAP trial. So the problems associated with CPAP early during the first night of therapy were eliminated. This study demonstrated that the most widespread reason for not initiating CPAP was general discomfort or displeasure with the CPAP device during the first night of therapy ${ }^{24}$ or during the CPAP titration period. ${ }^{29}$ Unfortunately, the results of this investigation may not be applicable to the general population in a tropical climate. The sample size of this study was small, and the study lasted only 4 weeks. A study with a longer duration is required to confirm clinical efficacy.

Perception of complaints and improvements in sleepiness and daily functioning appear to be the most significant factors determining treatment adherence, ${ }^{30}$ and different behavioral interventions, such as sufficient education, instruction, and support also play a significant role. ${ }^{31}$ A substantially greater benefit of heated humidification may be gained in patients with nasal complaints before initiating CPAP.

Harun Karamanlı MD

Department of Chronic Respiratory Failure, Ataturk Chest Disease and Chest Surgery Education and Research State Hospital Ankara, Turkey

\section{REFERENCES}

1. Partinen M, Guilleminault C. Daytime sleepiness and vascular morbidity at seven-year follow-up in obstructive sleep apnea patients. Chest 1990;97(1):27-32.

2. Grunstein RR. Sleep-related breathing disorders. 5. Nasal continuous positive airway pressure treatment for obstructive sleep apnoea. Tho$\operatorname{rax}$ 1995;50(10):1106-1113.

3. Engleman HM, Cheshire KE, Deary IJ, Douglas NJ. Daytime sleepiness, cognitive performance and mood after continuous positive airway pressure for the sleep apnoea/hypopnoea syndrome. Thorax 1993;48(9):911-914.

4. Redline S, Adams N, Strauss ME, Roebuck T, Winters M, Rosenberg C. Improvement of mild sleep-disordered breathing with CPAP compared with conservative therapy. Am J Respir Crit Care Med 1998;157(3):858-865.

5. Ruhle KH, Franke KJ, Domanski U, Nilius G. Quality of life, compliance, sleep and nasopharyngeal side effects during CPAP therapy with and without controlled heated humidification. Sleep Breath 2011; 15(3):479-485.

6. Richards GN, Cistulli PA, Ungar RG, Berthon-Jones M, Sullivan CE. Mouth leak with nasal continuous positive airway pressure increases nasal airway resistance. Am J Respir Crit Care Med 1996; 154(1):182-186.

7. Fischer Y, Keck T, Leiacker R, Rozsasi A, Rettinger G, Gruen PM. Effects of nasal mask leak and heated humidification on nasal mucosa in the therapy with nasal continuous positive airway pressure (nCPAP). Sleep Breath 2008;12(4):353-357.

8. Langmore SE, Terpenning MS, Schork A, Chen Y, Murray JT, Lopatin D, Loesche WJ. Predictors of aspiration pneumonia: how important is dysphagia? Dysphagia 1998;13(2):69-81.

9. Martins De Araújo MT, Vieira SB, Vasquez EC, Fleury B. Heated humidification or face mask to prevent upper airway dryness during 


\section{Heated Humidification and AdHerence to CPAP}

continuous positive airway pressure therapy. Chest 2000;117(1):142147.

10. Mehta S, Hill NS. Noninvasive ventilation. Am J Respir Crit Care Med 2001;163(2):540-577.

11. Non-invasive ventilation in acute respiratory failure. Thorax 2002; 57(3):192-211.

12. Massie CA, Hart RW, Peralez K, Richards GN. Effects of humidification on nasal symptoms and compliance in sleep apnea patients using continuous positive airway pressure. Chest 1999;116(2):403408.

13. Duong M, Jayaram L, Camfferman D, Catcheside P, Mykytyn I, McEvoy R. Use of heated humidification during nasal CPAP titration in obstructive sleep apnoea syndrome. Eur Respir J 2005;26(4): 679-685.

14. Wiest GH, Harsch IA, Fuchs FS, Kitzbichler S, Bogner K, Brueckl $\mathrm{WM}$, et al. Initiation of CPAP therapy for OSA: does prophylactic humidification during CPAP pressure titration improve initial patient acceptance and comfort? Respiration 2002;69(5):406-412.

15. Branson RD. Humidification of respired gases during mechanical ventilation: mechanical considerations. Respir Care Clin N Am 2006; 12(2):253-261.

16. Consensus statement on the essentials of mechanical ventilators1992. American Association for Respiratory Care. Respir Care 1992; 37(9):1000-1008.

17. Strumpf D, Carlisle C, Beadles S. Alternative methods of humidification during use of nasal CPAP. Respir Care 1990;35:217-221.

18. Rakotonanahary D, Pelletier-Fleury N, Gagnadoux F, Fleury B. Predictive factors for the need for additional humidification during nasal continuous positive airway pressure therapy. Chest 2001;119(2):460465.

19. Edelstein DR. Aging of the normal nose in adults. Laryngoscope 1996;106(S81):1-25.

20. Vig PS, Zajac DJ. Age and gender effects on nasal respiratory function in normal subjects. Cleft Palate Craniofac J 1993;30(3):279-284.

21. Sakakura Y, Ukai K, Majima Y, Murai S, Harada T, Miyoshi Y. Nasal mucociliary clearance under various conditions. Acta OtoLaryngologica 1983;96(1-2):167-173.
22. Nilius G, Franke KJ, Domanski U, Schroeder M, Ruhle KH. Effect of APAP and heated humidification with a heated breathing tube on adherence, quality of life, and nasopharyngeal complaints. Sleep Breath 2015;1-7.

23. Mortimore IL, Whittle AT, Douglas NJ. Comparison of nose and face mask CPAP therapy for sleep apnoea. Thorax 1998;53(4):290292.

24. Russell T. Enhancing adherence to positive airway pressure therapy for sleep disordered breathing. Semin Respir Crit Care Med 2014; 35(5):604-612.

25. Gay P, Weaver T, Loube D, Iber C. Evaluation of positive airway pressure treatment for sleep related breathing disorders in adults. Sleep 2006;29(3):381-401.

26. Winck JC, Delgado JL, Almeida JM, Marques JA. Heated humidification during nasal continuous positive airway pressure for obstructive sleep apnea syndrome: objective evaluation of efficacy with nasal peak inspiratory flow measurements. Am J Rhinol 2002;16(3): 175-177.

27. Ryan S, Doherty LS, Nolan GM, McNicholas WT. Effects of heated humidification and topical steroids on compliance, nasal symptoms, and quality of life in patients with obstructive sleep apnea syndrome using nasal continuous positive airway pressure. Public Health 2015.

28. Soudorn, C, Muntham D, Reutrakul S, Chirakalwasan N. Effect of heated humidification on CPAP therapy adherence in subjects with obstructive sleep apnea with nasopharyngeal symptoms. Respir Care 2016 May 24. pii: respcare.04536. [Epub ahead of print].

29. Wolkove N, Baltzan M, Kamel H, Dabrusin R, Palayew M. Longterm compliance with continuous positive airway pressure in patients with obstructive sleep apnea. Can Respir J 2008;15(7):365-369.

30. Weaver TE, Grunstein RR. Adherence to continuous positive airway pressure therapy: the challenge to effective treatment. Proc A Thorac Soc 2008;5(2):173-178.

31. Hoy CJ, Vennelle M, Kingshott RN, Engleman HM, Douglas NJ. Can intensive support improve continuous positive airway pressure use in patients with the sleep apnea/hypopnea syndrome? Am J Respir Crit Care Med 1999;159(4):1096-1100. 